\title{
Further Delineation of the dup(3q) Syndrome
}

\author{
Golder N. Wilson, Majed Dasouki, and Mason Barr, Jr. \\ Section of Pediatric Genetics, Department of Pediatrics, University of Michigan, \\ Ann Arbor
}

\begin{abstract}
Three patients with duplication of $3 \mathrm{q}$ regions ranging from $3 \mathrm{q} 25 \rightarrow \mathrm{qter}$ to the entire long arm provide additional documentation of the dup(3q) malformation syndrome. Data on 40 cases now reported define a characteristic face with hirsutism, synophrys, broad nasal root, anteverted nares, downturned corners of the mouth, micrognathia, and malformed ears recognizable even in the 30-week fetus and distinct from that of the Brachmann-de Lange syndrome. Other characteristic anomalies include congenital heart anomalies involving primarily septal defects, hand malformations including simian creases, abnormal dermatoglyphics, clinodactyly or camptodactyly, omphalocele, skeletal anomalies, and genitourinary malformations. Severe mental and growth retardation are common in those patients $(64 \%)$ who survive the first year. Chromosome study of relatives is extremely important for counseling because only 10 of 40 cases represented de novo duplications.
\end{abstract}

Key words: dup(3q), multiple congenital anomalies/mental retardation (MCA/MR) syndrome

\section{INTRODUCTION}

Duplication $3 q$ syndrome was first reported as "familial de Lange syndrome with chromosomal abnormalities" by Falek et al [1966] before banding studies associated duplication of the $3 \mathrm{q} 21 \rightarrow 3$ qter region with a distinctive phenotype [Hirschhorn et al, 1973; Boué et al, 1974; Allderdice et al, 1975]. The latter cases also had $\operatorname{del}(3 \mathrm{q} 25 \rightarrow \mathrm{pter})$ due to segregation of a pericentric inversion, but the phenotype of isolated dup(3q) is virtually identical, as first documented by Chiyo et al [1976] and reviewed by Steinbach et al [1981]. The mild manifestations of isolated del(3p) [Wilson et al, 1982] are apparently obscured in the phenotype $\operatorname{del}(3 p) / \operatorname{dup}(3 q)$. Although a previous report of two $\operatorname{dup}(3 q)$ patients from our laboratory [Wilson et

Received for publication October 31, 1984; revision received February 11, 1985.

Address reprint requests to Dr. Golder N. Wilson, Department of Pediatrics, D1225 Medical Professional Building, University Hospitals, Ann Arbor, MI 48109. 
al, 1978] emphasized the resemblance of $\operatorname{dup}(3 q)$ syndrome to the Brachmann-de Lange syndrome, there is no question that these syndromes are separate entities with distinctive facial changes and malformation patterns [Francke, 1978; Francke and Opitz, 1979]. Here we report three additional cases of the dup(3q) syndrome including one with duplication of the entire long arm.

\section{CLINICAL REPORTS}

Patient 1

This male infant was born at term after an uncomplicated pregnancy to a 22year-old gravida 2, para 1 white woman. The father was 23 years old, and the family history was unremarkable. Measurements at birth included a weight of 1,870 gm, length $42 \mathrm{~cm}$, occipitofrontal head circumference (OFC) $32 \mathrm{~cm}$ (all $<3 \mathrm{rd}$ centile), and an interpupillary distance of $4.0 \mathrm{~cm}$ (50th centile). The infant (Fig. 1A,B) had a broad nasal root, right epicanthal fold, anteverted nares, long upper lip with flat philtrum, thin vermilion border of upper lip, downturned corners of the mouth, micrognathia, posteriorly augulated malformed ears with preauricular dimples, dysplastic corneal bands with irregular pupillary margins, cataracts, and highly arched palate due to hypertrophic lateral palatine ridges. The neck appeared short with pterygium colli. The thorax was flattened with the appearance of widely spaced
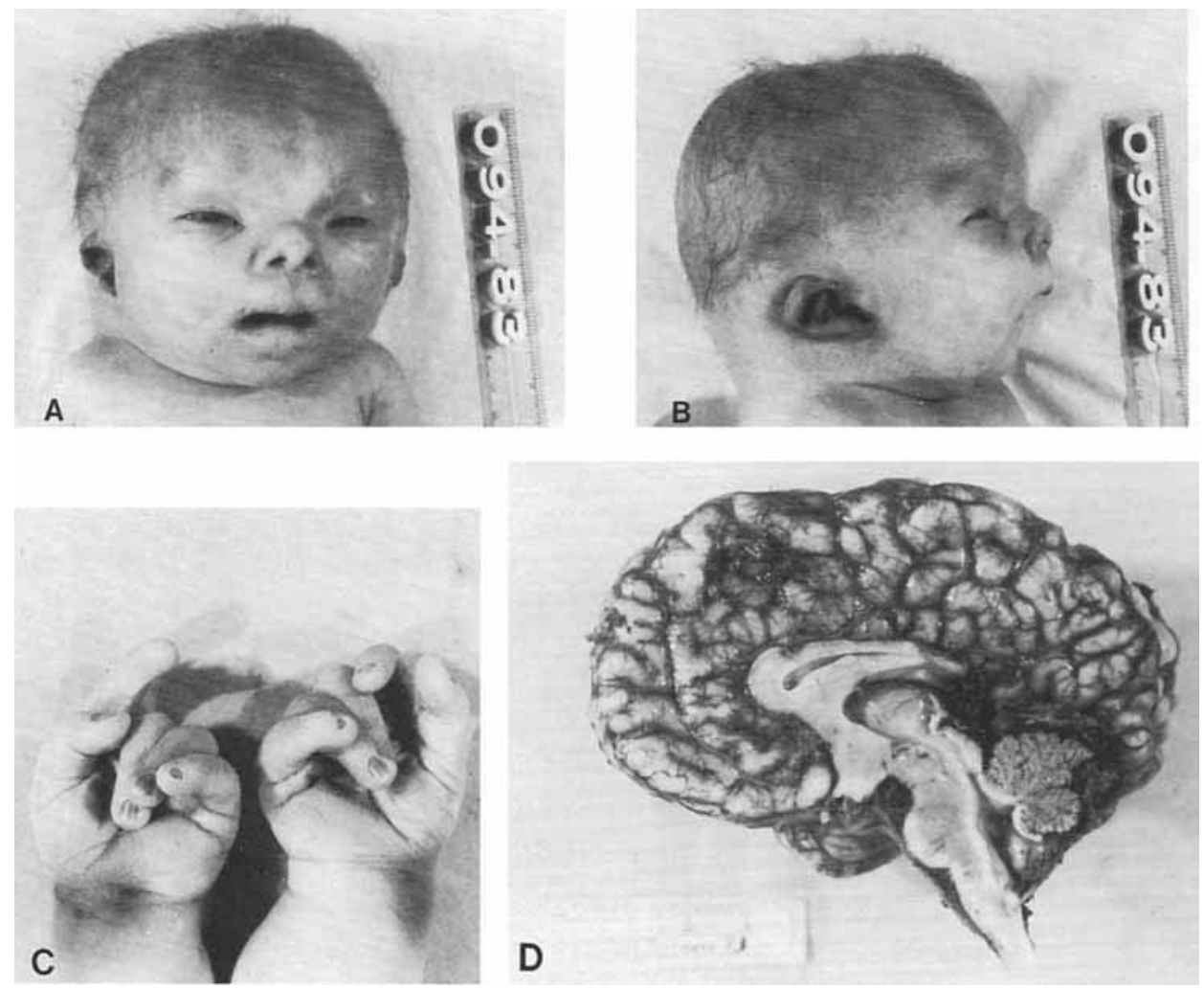

Fig. 1. Frontal view (A), lateral view (B), hands (C), and sagittal midline view of the brain (D) of patient 1 . 
nipples, but the interareolar distance was normal. Multiple cardiac defects-double outlet right ventricle, subaortic ventricular septal defect, aortic insufficiency, atrial septal defect-with pulmonary artery hypertension and persistent transitional circulation were documented by cardiac catheterization. There was a small abdominal omphalocele, diastasis recti, and bilateral cryptorchidism. There was a single palmar crease on the left, camptodactyly (Fig. 1C), hypoplastic nails, and dermatoglyphic arch patterns on fingertips. Skeletal survey demonstrated hypoplastic first ribs, absent twelfth ribs, and short sternum.

Apgar scores were 2 and 4 at birth; thereafter the child deteriorated progressively despite intubation, respirator, and Dopamine therapy. An initial platelet count was 21,000 but rose to 269,000 after antibiotic therapy. Results of other routine hematologic and blood chemistry studies and of a TORCH screen were normal. Death occurred at $14 \mathrm{hr}$; autopsy findings included thymic and pulmonary hypoplasia, splenomegaly, double left renal arteries, and a globular pancreas. Brain anomalies (Fig. 1D) included polymicrogyria, hypoplastic olfactory bulbs, elongated optic nerves, and increased hindbrain-midbrain angulation. Cytogenetic studies (see Fig. 4A) showed duplication of the $3 q 11 \rightarrow 3 q$ ter region due to segregation of a maternal reciprocal translocation $46, X Y t(3 ; 15)(q 11 ; p 11)$.

\section{Patient 2}

This male infant was electively terminated at 30 weeks of gestation by a 25 year-old white woman who had had a prior 10-week spontaneous abortion. The father was 27 and the family history was otherwise unremarkable. An ultrasound study at 26 weeks had shown bilateral fetal pleural effusions with lung hypoplasia and marked scalp, neck, and thoracic edema. A transabdominal fetal thoracentesis did not improve lung expansion but yielded the karyotype shown in Figure 4B. Autopsy findings included a length of $40.5 \mathrm{~cm}$ (50th centile), weight of $1.84 \mathrm{~kg}$ ( $>97$ th centile), OFC of $30 \mathrm{~cm}$ (80th centile), an abnormal face (Fig. 2A) with hypertrichosis, synophrys, broad nasal root, anteverted nares, long upper lip, and downturned corners of the mouth; short neck with edema of the nape; U-shaped cleft of the soft palate and micrognathia; broad-appearing chest with normal interareolar distance; ventricular septal defect with an aberrant right subclavian artery; ambiguous genitalia (Fig. 2B) with a small phallus, hypospadias, absent scrotal folds, and testes in the inguinal canals; bilateral simian creases with hyperconvex clubbed nails; abdominal ascites with an enlarged spleen and a centrally placed liver; bilateral calcaneovalgus deformity with rocker-bottom feet and prominent heels; and a normal-sized brain without gross malformation.

Chromosome study from the pleural fluid (Fig. 4B) showed duplication of the $3 q 25 \rightarrow 3$ qter region due to segregation of a paternal reciprocal translocation $46, \mathrm{XYt}(3$; 13)(q25; q32).

\section{Patient 3}

This 5-month-old female was born at term after an uncomplicated gestation to a 26-year-old gravida 3, para 2 Arabic woman. Birth weight was $2.28 \mathrm{~kg}$. The father is a first cousin and is $\mathbf{3 0}$ years old. Following a breech delivery, the infant required prolonged hospitalization for failure to grow, cleft palate repair, and feeding difficulties. Physical examination showed a length of $56 \mathrm{~cm}$, weight of $5.3 \mathrm{~kg}$, and an OFC of $38 \mathrm{~cm}$ with an interpupillary distance of $3.5 \mathrm{~cm}$. The weight was at the $3 \mathrm{rd}$ centile 

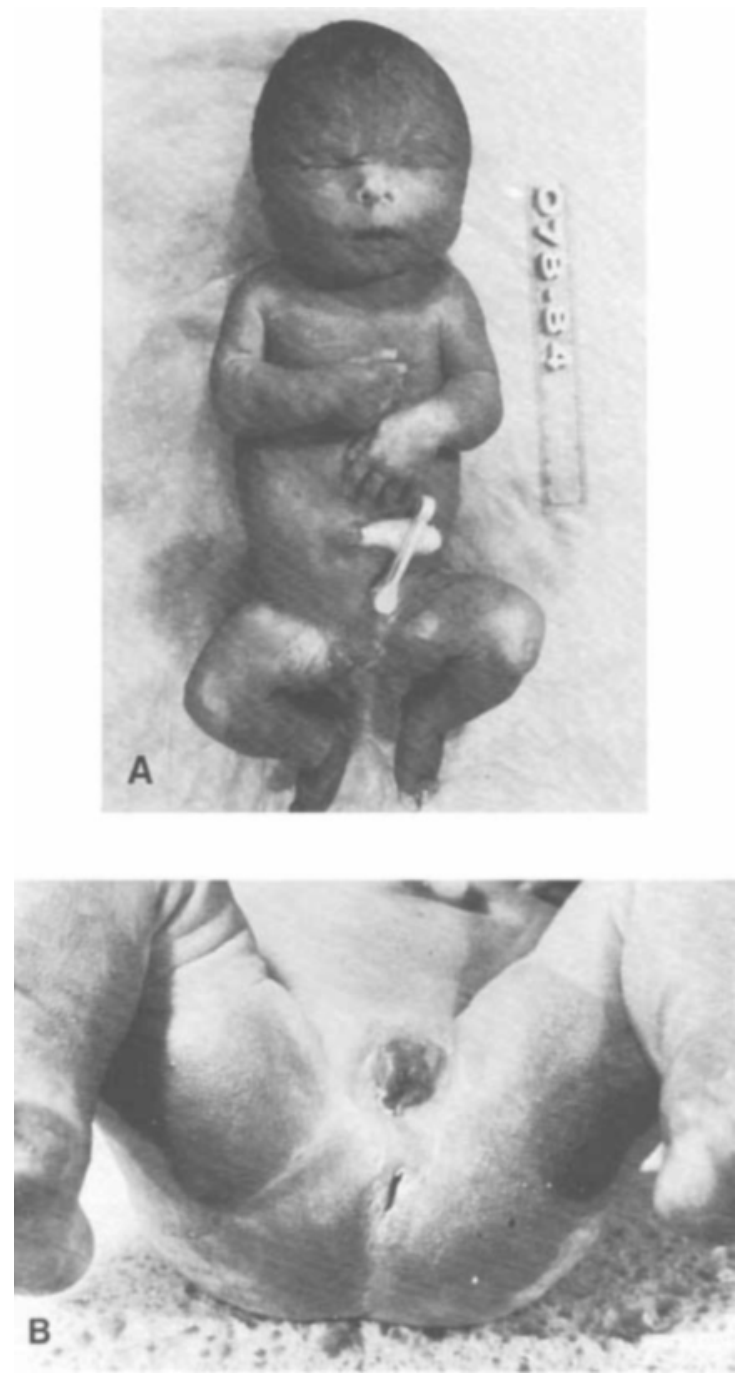

Fig. 2. Frontal view (A) and genitalia (B) of patient 2 .

for age 5 months and the other measurements were just below the 3rd centile. There was an unusual head shape (Fig. 3) due to metopic and sagittal suture synostosis and an abnormal facial appearance with hypertrichosis, synophrys, upslanting palpebral fissures, broad nasal root, anteverted nares, downturned corners of the mouth, and anteflexed, malformed ears. There was a repaired cleft soft palate and bilateral anterior ear dimples. Results of specialty evaluations for eye or cardiac anomalies were normal. There was a bilateral bridged palmar crease with camptodactyly of all fingers. There was hyperflexia and spasticity of the lower limbs.

Chromosome study (Fig. 4C) showed an extra chromosome containing the short arm and centromere of 14 attached to bands $3 \mathrm{q} 27 \rightarrow 3 \mathrm{qter}$ as demonstrated by a maternal reciprocal translocation $46, \operatorname{XXt}(3 ; 14)(\mathrm{q} 27 ; 12)$. Thus the child's chromosome constitution was $47, \mathrm{XX}+\operatorname{der}(14)(14 \mathrm{pter} \rightarrow \mathrm{q} 12:: 3 \mathrm{q} 27 \rightarrow \mathrm{qter})$. 

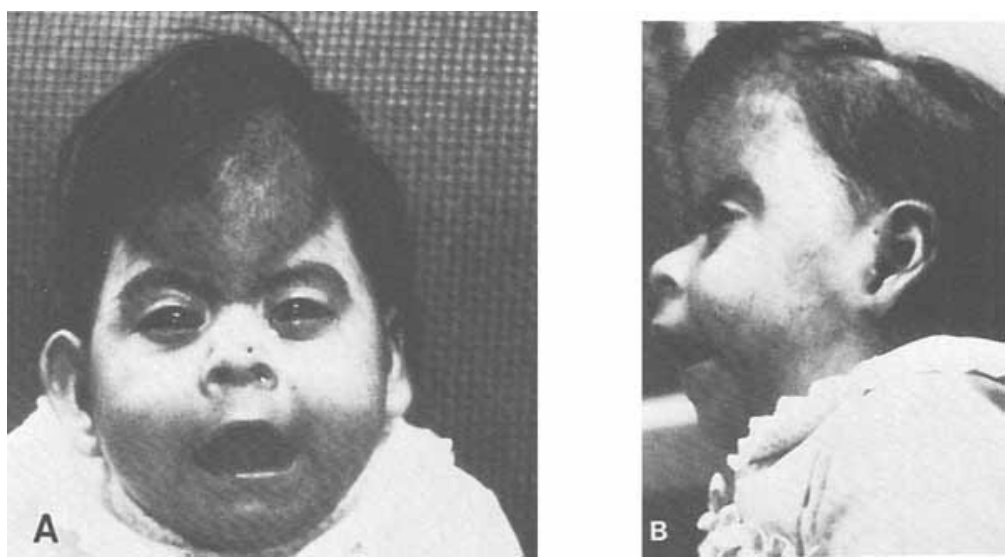

Fig. 3. Frontal and lateral views of patient 3 .

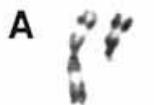

3

B

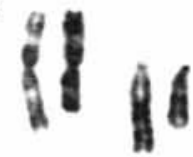

3

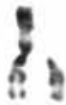

15

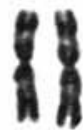

3

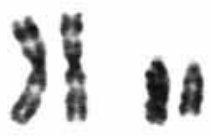

313
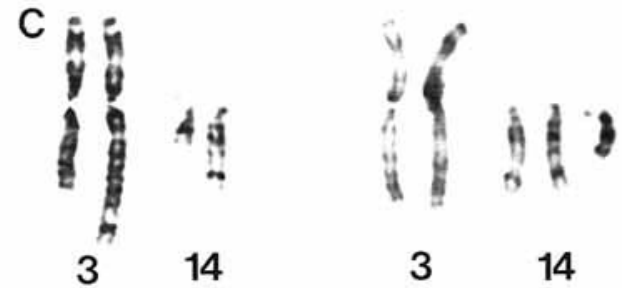

314

Fig. 4. Partial karyotypes from patients $1-3$ and their translocation carrier parents. A, chromosomes 3 and 15 from patient 1 (right) demonstrating duplication of the $3 \mathrm{q} 11 \rightarrow 3$ qter region and deficiency of the $15 \mathrm{p} 11 \rightarrow 15$ pter region due to segregation of a balanced translocation $46, \mathrm{XYt}(3 ; 15)(\mathrm{q} 11 ; \mathrm{p} 11)$ from the mother (left). B, chromosomes 3 and 13 from patient 2 (right) demonstrating duplication of the $3 q 25 \rightarrow 3 q t e r$ region and deficiency of the $15 q 32 \rightarrow 15$ qter region due to segregation of a balanced translocation 46,XYt(3;13)(q25; q32) from the father (left). C, chromosomes 3 and 14 from patient 3 (right) demonstrating duplication of the $3 \mathrm{q} 27 \rightarrow 3$ qter and $14 \mathrm{q} 12 \rightarrow 14 \mathrm{qter}$ regions due to $3: 1$ nondisjunction from a balanced translocation $46, \operatorname{XXt}(3 ; 14)(q 27 ; q 12)$ in the mother (left).

\section{RESULTS AND DISCUSSION}

Table 1 summarizes the manifestations of 40 cases of the dup(3q) syndrome as tabulated in the review of Steinbach et al [1981], the single case report of Rosenfeld et al [1981], and the three cases reported here. We have been informed that a dup(3q) 
TABLE I. Clinical Manifestations of the dup(3q) Syndrome*

\begin{tabular}{lrr}
\hline & No. & $\%$ \\
\hline Female sex & $23 / 40$ & 58 \\
Death before 12 months & $14 / 39$ & 36 \\
Hypertrichosis & $25 / 29$ & 86 \\
Abnormal head shape & $35 / 38$ & 92 \\
Upslanting palpebral fissures & $15 / 27$ & 56 \\
Broad nasal root & $30 / 30$ & 100 \\
Anteverted nares & $29 / 32$ & 91 \\
Long upper lip & $23 / 27$ & 85 \\
Maxillary prognathia & $18 / 21$ & 86 \\
Downturned corners of mouth & $18 / 22$ & 82 \\
Highly arched palate & $22 / 22$ & 100 \\
Cleft palate & $18 / 25$ & 79 \\
Malformed auricles & $29 / 31$ & 94 \\
Short or webbed neck & $26 / 28$ & 93 \\
Abnormal chest & $23 / 26$ & 89 \\
Cardiac defects & $23 / 31$ & 75 \\
Omphalocele & $3 / 13$ & 23 \\
Renal or urinary tract anomalies & $11 / 23$ & 48 \\
Genital abnormalities & $17 / 28$ & 61 \\
Clinodactyly & $27 / 30$ & 90 \\
Hypoplastic nails & $9 / 14$ & 64 \\
Simian crease & $17 / 23$ & 74 \\
Talipes & $14 / 22$ & 64 \\
Other skeletal anomalies & $17 / 26$ & 66 \\
Brain anomalies/seizures & $19 / 23$ & 83 \\
\hline
\end{tabular}

*Modified from the table of Steinbach et al [1981], including the case of Rosenfeld et al [1981], the present three cases, and eliminating the case report duplicated in the papers of Boué et al [1974] and Hirschhorn et al [1973].

patient reported by Hirschhorn et al [1973] was inadvertently included in the paper of Boué et al [1974] and therefore counted twice in the summary by Steinbach et al [1981]-Table I corrects for this redundancy. The face of dup (3q) syndrome is quite distinctive and includes hypertrichosis, synophrys, broad nasal root, anteverted nares, downturned corners of the mouth with a long upper lip, malformed ears, and a prominent maxilla. Craniosynostosis is common, as is a short neck and a broad chest with the appearance of widely spaced nipples. Hand anomalies include clinodactyly, camptodactyly, simian creases, nail hypoplasia, and may in extreme cases resemble the clenched fist typical of trisomy 18 (Fig. 1C). Severe mental retardation with underlying brain anomalies and seizures, omphalocele, glaucoma, heart and kidney disease, as well as diverse skeletal anomalies including talipes equinovarus cause a severe clinical course, with 15 of 39 patients not surviving infancy. Resemblance to the Brachmann-de Lange syndrome is superficial, as emphasized by Francke and Opitz [1979], and the two syndromes are easily distinguished during infancy. A detailed comparison of the manifestations [Wilson et al, 1978] indicates intrauterine growth retardation, prominent philtrum, proximally placed thumbs, oligodactyly/ phocomelia, and syndactyly of toes 2 and 3 to be more frequent in the Brachmann-de Lange syndrome, whereas craniosynostosis, cleft palate, and urinary tract anomalies are more typical of $\operatorname{dup}(3 q)$. 
Most dup(3q) patients have arisen from segregation of parental rearrangements, as indicated by the present three cases derived from translocations between chromosome 3 and D group chromosomes. Of the 40 cases summarized in Table I, 30 derived from parental rearrangements involving a pericentric inversion of chromosome 3 (11 cases) or balanced translocations between chromosomes 3 and 2 (four cases), 13, 15 , 21 (two cases each), 5, 9, 12, 14, and 22 (one case each). Duplication of the 3 q25 $\rightarrow$ qter region seems sufficient to generate the characteristic face, although a slightly more severe phenotype is generated by complete duplication of $3 q$ (case 1 ). Concurrent deleted or duplicated chromosome regions arising from parental rearrangements in $\operatorname{dup}(3 q)$ patients, as illustrated by the three cases reported here, seem to have little influence on the characteristic phenotype. The potency of the $3 q$ terminus for dysmorphogenesis is further illustrated by the characteristic face of the $\operatorname{dup}(3 q)$ case reported by Oorthuys et al [1981], which, because it involved an X;3 translocation and manifestations of the Ullrich-Turner syndrome, was not included in this review.

\section{ACKNOWLEDGMENTS}

The authors acknowledge Beth Cox, Mark Bush, and Emerson Baty for performing the cytogenetic studies.

\section{REFERENCES}

Allderdice PW, Browne N, Murphy DP (1975): Chromosome 3 duplication q21 $\rightarrow$ qter deletion p25 $\rightarrow$ pter syndrome in children of carriers of a pericentric inversion inv (3)(p25q21). Am J Hum Genet 27:699-718.

Boué J, Hirschhorn K, Lucas M, Gautier M, Moszer M, Bach CH (1974): Aneusomies de recombinaison. Conséquences d'une inversion péricentrique d'un chromosome 3 paternal. Ann Pédiatr 21:567-573.

Chiyo H-A, Kuroki Y, Matsui I, Niitsu N, Nakagome Y (1976): A case of partial trisomy 3q. J Med Genet 13:535-538.

Falek A, Schmidt R, Jervis GA (1966): Familial deLange syndrome with chromosome abnormalities. Pediatrics 37:92-101.

Francke U (1978): Clinical syndromes associated with partial duplications of chromosomes 2 and 3: dup (2p), dup ( $2 q)$, dup (3p), dup (3q). New York: Alan R. Liss, Inc., for The National FoundationMarch of Dimes. BD: OAS 14(viC):191-217.

Francke U, Opitz JM (1979): Chromosome 3q duplication and the Brachmann de Lange syndrome (BDLS). Letter to the editor. J Pediatr 95:161-162.

Hirschhorn K, Lucas M, Wallace I (1973): Precise identification of various chromosomal abnormalities. Ann Hum Genet 36:375-379.

Oorthuys JWE, Slater RM, Barrowclough H, deKleine MJK (1981): Partial trisomy 3q due to a de novo translocation $\mathrm{t}(\mathrm{X} ; 3)(\mathrm{p} 21 ; \mathrm{q} 12)$. Clin Genet 20:130-134.

Rosenfeld W, Verma RS, Jhaveri RC, Estrada R, Evans H, Dosik H (1981): Duplication 3q: Severe manifestations in an infant with duplication of a short segment of 3q. Am J Med Genet 10:187192.

Steinbach P, Adkins WN Jr, Caspar H, Dumars KW, Gebauer J, Gilbert EF, Grimm T, Habedank M, Hansmann I, Herrmann J, Kaveggia EG, Langenbeck U, Meisner LF, Najafzadeh TM, Opitz JM, Palmer CG, Peters HH, Scholz W, Tavares AS, Wiedeking C (1981): The dup(3q) syndrome: Report of eight cases and review of the literature. Am J Med Genet 10:159-177.

Wilson GN, Hieber VC, Schmickel RD (1978): The association of chromosome 3 duplication and the Cornelia de Lange syndrome. J Pediatr 93:783-788.

Wilson GN, Pooley J, Parker J (1982): The phenotype of ring chromosome 3. J Med Genet 6:471-473.

Edited by John M. Opitz and James F. Reynolds 